\title{
Hematúria macroscópica em equinos associada à infecção por Leptospira interrogans*
}

\section{Macroscopic haematuria in horses associated with Leptospira interrogans infection}

\author{
Cíntia Ferreira, ${ }^{* *}$ Maristela Silveira Palhares, ${ }^{* * *}$ Ubiratan Pereira de Melo, ${ }^{* *}$ Lucas Tadeu Silva, ${ }^{* * *}$ \\ Fabíola Oliveira Paes Leme, ${ }^{* * *}$ José Monteiro da Silva Filho***
}

\begin{abstract}
Resumo
Hematúria é uma grave manifestação clínica de doença do sistema urinário, ocorrendo sob as formas micro ou macroscópica. Neste artigo relatam-se dois casos de hematúria macroscópica associada à infecção por Leptospira interrogans sorogrupo Canicola. O exame clínico inicial revelou hematúria macroscópica, taquicardia, taquipneia, febre, elevação do tempo de perfusão capilar, hipomotilidade intestinal, além de icterícia da mucosa oral. Leucocitose, proteinúria, glicosúria, piúria e azotemia foram achados comuns aos dois casos. Teste de Soroaglutinação Microscópica foi realizado para titulação de anticorpos contra Leptospira interrogans. Tratamento incluiu medidas terapêuticas de suporte (fluidoterapia), controle da hematúria e antibioticoterapia. Sete dias após manifestação dos sinais clínicos iniciais, ambos animais receberam alta hospitalar após remissão dos sinais clínicos.
\end{abstract}

Palavras-chaves: Azotemia, creatinina, icterícia, leucocitose, leptospirose.

\begin{abstract}
Haematuria is a serious clinical manifestation of urinary system disease, occurring in micro or macroscopic forms. In this article two cases of macroscopic haematuria associated with Leptospira interrogans serogroup Canicola infection are related. The initial clinical examination revealed macroscopic haematuria, tachycardia, tachypnea, fever, increased capillary perfusion time, intestinal hypomotility, in addition to jaundice of the oral mucosa. Leukocytosis, proteinuria, glycosuria, pyuria and azotemia were common findings in both cases. Microscopic serum agglutination test was performed for titration of antibodies against Leptospira interrogans. Treatment included supportive therapeutic measures (fluid therapy), hematuria control and antibiotic therapy. Seven days after the manifestation of the initial clinical signs, both animals were discharged from the hospital without complications.
\end{abstract}

Keywords: Azotemia, creatinine, jaundice, leukocytosis, leptospirosis.

\section{Introdução}

Hematúria é uma grave manifestação clínica de doença do sistema urinário, ocorrendo sob as formas micro ou macroscópica. Embora ambas as formas sejam importantes, os pacientes são encaminhados para atendimento somente quando a forma macroscópica é observada. As causas mais comuns são ruptura uretral, uretrite, pielonefrite, nefrite verminótica, neoplasia vesical e/ou renal, além de urolitíase. Causas menos comum incluem toxicose por cantaridina, cistite bacteriana, administração crônica de antiinflamatórios não esteroidais, alterações do endotélio vascular e leptospirose (MELO et al., 2009a; MACÊDO et al., 2017; SMITH et al., 2017).

A leptospirose é uma doença multissistêmica, causada por leptospiras patogênicas, caracterizada por ampla variedade de manifestações clínicas que variam desde infecção inaparente, doença clínica febril anictérica auto-limitante até doença fulminante e fatal (BATISTA et al., 2015; BECIROVIC et al., 2020; FURLANELLO; REALE, 2020). Em equinos, a maioria das infecções apresenta caráter subclínico e representa um grave problema, pois o agente pode ser eliminado na urina dos animais portadores (FERREIRA et al., 2008; LASTA et al., 2013; FARIAS et al., 2020). Em estudo realizado por Farias et al. (2020) os sorovares de maior incidência em equinos com leptospirose subclínica foram Bratislava 37,23\% (35/94), Icterohaemorrhagiae $23,4 \%$ (22/94) e Grippotyphosa 11,7\% (11/94). No equino adulto, a leptospirose está comumente associada a aborto ou uveíte, sendo a espécie mais comumente envolvida na uveíte recorrente equina (URE) a $L$. interrogans sorogrupo Australis sorovar Grippothyphosa (FOUCHÉ et al., 2020).

A leptospirose é considerada a zoonose mais difundida no mundo. A fonte de infecção para os seres humanos é geralmente o contato direto ou indireto com a urina de um animal infectado. A incidência é significativamente maior em países de clima

\footnotetext{
*Recebido em 3 de junho de 2021 e aceito em 24 de agosto de 2021.

**Faculdade Maurício de Nassau (Uninassau), Campus Natal/RN, Natal, Rio Grande do Norte. Autor para correspondência: cinvetmelo@yahoo.com.br

${ }^{* * *}$ Escola de Veterinária da UFMG, Departamento de Clínica e Cirurgia Veterinária, Belo Horizonte, Minas Gerais.

****Médico Veterinário autônomo.
} 
quente do que em regiões temperadas em decorrência da maior sobrevida das leptospiras no ambiente em condições quentes e úmidas. No entanto, a maioria dos países tropicais também são países em desenvolvimento, e há maiores oportunidades de exposição da população humana a animais infectados, seja animais domésticos ou selvagens (LEVETT, 2001).

As manifestações clínicas das leptospiroses decorrem de lesão vascular generalizada com comprometimento do endotélio de pequenos vasos, extravasamento de sangue, migração de leptospiras para os tecidos e relativa hipóxia local que resultam em lesões secundárias em órgãos como rim, fígado, pulmão, coração e musculatura (BATISTA et al., 2015).

A leptospirose apresenta forte significado sócio-econômicocultural, estando relacionada a fatores como crescimento desordenado dos grandes centros urbanos, movimentos migratórios, péssimas condições de saneamento básico. O acúmulo de lixo em locais inadequados promove a expansão da população de murídeos, considerados as principais fontes de infecção para outras espécies incluindo a humana, canina e equina (FERREIRA et al., 2008; AJJIMARUNGSI et al., 2020).

Este trabalho tem como objetivo relatar dois casos de hematúria macroscópica em equino associada à infecção por Leptospira interrogans sorogrupo Canicola.

\section{Relato do caso}

Caso 1: Equino sem raça definida, macho, $280 \mathrm{~kg}$ e idade aproximada de 4,5 anos foi atendido no Hospital Veterinário da Escola de Veterinária da UFMG (HV-UFMG) com histórico de hematúria que perdurava por mais de 24 horas. $O$ equino era mantido em baia com livre acesso a piquete, e alimentado com capim picado e concentrado comercial. O animal não apresentava histórico de vacinações, e havia sido vermifugado há dois meses. $O$ exame clínico inicial revelou taquicardia (84 bpm), taquipnéia (33 mrm), febre $\left(40^{\circ} \mathrm{C}\right)$, elevação do tempo de perfusão capilar (> 3seg.), hipomotilidade intestinal em ambos antímeros, além de icterícia da mucosa oral com formação de halo endotoxêmico. Hematúria (Figura 1) foi observada durante o exame clínico. A auscultação pulmonar demonstrou estertores pulmonares em ambos hemitórax.

Figura 1: Hematúria macroscópica em equino.
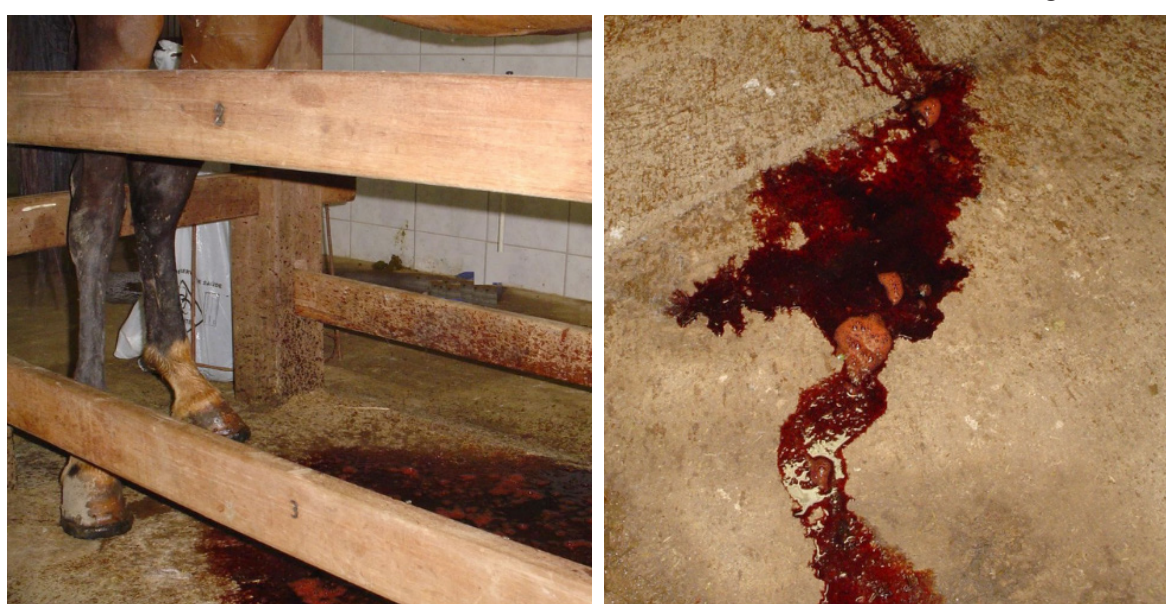

Caso 2: Equino, macho, Quarto de milha, 19 anos, $400 \mathrm{~kg}$, foi encaminhado para atendimento no HV-UFMG. Segundo relato do veterinário responsável pelo atendimento clínico inicial uma grande quantidade de coágulos sanguíneos foi visualizada na baia. Ao ser examinado na fazenda, o animal apresentava dificuldade de micção, e a palpação transretal revelou distensão vesical. Seis litros de urina de coloração vermelho-escuro foram obtidos por meio da cateterização vesical. Segundo o proprietário no local havia grande quantidade de ratos e cães errantes em contato direto com o alimento/água dos animais.

Ao exame clínico inicial constatou-se taquicardia (59 bpm), taquipneia ( $28 \mathrm{mrm}$ ), elevação do tempo de perfusão capilar (3 seg), febre $\left(39,5^{\circ} \mathrm{C}\right)$, diminuição do apetite, postura anti-álgica nos membros posteriores e palidez de mucosas. À auscultação pulmonar nenhuma anormalidade foi observada.

Síbalas pequenas, ressecadas e recobertas por quantidade moderada de muco, além de compactação de cólon menor e sensibilidade dolorosa à palpação da borda caudal do rim esquerdo foram identificados durante a palpação transretal em ambos os casos.

Fitas reagentes para urinálise (dipsticks) foram utilizadas para diferenciação da descoloração da urina no momento do exame clínico inicial. Além disso, procedeu-se a centrifugação de uma amostra de urina de ambos os casos. Após centrifugação observou-se uma camada de hemácias e urina clara no sobrenadante. A sedimentoscopia da urina de ambos os equinos revelou > 15 hemácias/campo de grande aumento.

Para identificação da origem da hemorragia foi realizada ultrassonografia vesical e renal. O sonograma renal não apresentou alterações estruturais ou de ecogenicidade. Ao sonograma vesical não foram observadas alterações na espessura de parede ou presença de massas e/ou urólitos na bexiga. Em ambos os casos, grande quantidade de grumos hiperecogênicos foram visualizados no sonograma vesical, provavelmente coágulos. A lista de diagnósticos diferenciais incluiu cistite bacteriana, leptospirose, hematúria idiopática e pielonefrite.

Amostras de sangue foram colhidas por venopunção central para avaliação hematológica e bioquímica sérica. Devido a restrições financeiras de um dos proprietários (caso 1), houve limitação na realização de exames laboratoriais. Os dados hematológicos e bioquímicos do estão sumarizados nas tab. 1 e 2, respectivamente.

Amostras de sangue de ambos os casos foram colhidas para realização de sorologia para identificação de anticorpos contra Leptospira interrogans no momento do atendimento clínico. O teste diagnóstico realizado foi o Teste de Soroaglutinação Microscópica (SAM), utilizando os sorogrupos Canicola, Ballum, Sejroe, Pomona, e Icterohaemorrhagiae como antígenos. A titulação máxima obtida em ambos os casos foi 1:400 para Leptospira interrogans sorogrupo Canicola, e os demais sorogrupos foram negativos. Em ambos os casos, a microscopia de campo escuro foi negativa para Leptospira interrogans. 
Tabela 1: Resultados da avaliação hematológica no $1^{\circ}$ e $7^{\circ}$ dia após o episódio de hematúria macroscópica.

\begin{tabular}{|c|c|c|c|c|c|}
\hline & \multicolumn{2}{|c|}{ Caso 1} & \multicolumn{2}{|c|}{ Caso 2} & \multirow[b]{2}{*}{ Valores de Referência } \\
\hline & $1^{\circ} \mathrm{dia}$ & $7^{\circ}$ dia & $1^{\circ} \mathrm{dia}$ & $7^{\circ}$ dia & \\
\hline Hematócrito & 10,6 & 25 & 29 & 28 & $32-52 \%$ \\
\hline Hemácias & 2,27 & 5,9 & 7,1 & 7,2 & $6,500-12,500 \mathrm{cel} / \mu \mathrm{l}$ \\
\hline Hemoglobina & 3,6 & 9 & 11,1 & 12,2 & $11-19 \mathrm{~g} / \mathrm{dl}$ \\
\hline VCM & 47 & 47 & 40,8 & 38,8 & $36-52 \mathrm{fl}$ \\
\hline $\mathrm{CHCM}$ & 15,9 & 31 & 38,3 & 43,57 & $34-39 \mathrm{~g} / \mathrm{dl}$ \\
\hline $\mathrm{HCM}$ & 33,7 & 17 & 15,7 & 17 & $12,3-19,7 \mathrm{pg}$ \\
\hline Leucócitos totais & 19,100 & 12,800 & 15,000 & 13,400 & $6,000-12,500 \mathrm{cel} / \mu \mathrm{l}$ \\
\hline Bastonetes & 0 & 0 & 1 & 0 & $0-100 \mathrm{cel} / \mu \mathrm{l}$ \\
\hline Segmentados & 15,089 & 9,350 & 12,900 & 9,648 & $2,700-6,700 \mathrm{cel} / \mu \mathrm{l}$ \\
\hline Eosinófilos & 764 & 750 & 0 & 0 & $0-900 \mathrm{cel} / \mu \mathrm{l}$ \\
\hline Linfócitos & 2,292 & 2100 & 900 & $2,948^{*}$ & $1,500-5,000 \mathrm{cel} / \mu \mathrm{l}$ \\
\hline Monócitos & 573 & 400 & 1050 & $804^{*}$ & $0-800 \mathrm{cel} / \mu \mathrm{l}$ \\
\hline Basófilos & 392 & 200 & 0 & 0 & $0-200 \mathrm{cel} / \mu \mathrm{l}$ \\
\hline Plaquetas & 293,000 & 222,000 & 153,000 & 218,000 & $100,000-300,000 / \mu l$ \\
\hline
\end{tabular}

Obs.: *Foram observados na lâmina monócitos ativados e linfócitos reativos.

Baseado na anamnese, exame clínico e achados laboratoriais diagnosticou-se leptospirose aguda em ambos os casos. Após o diagnóstico clínico, os animais foram tratados com: (1) fluidoterapia enteral $(5 \mathrm{ml} / \mathrm{kg} / \mathrm{h})$, via oral durante 24 horas; (2) ácido tranexâmico ${ }^{1}(4 \mathrm{mg} / \mathrm{kg})$, a cada 12 horas por via intramuscular (IM) durante 3 dias; (3) dipirona ${ }^{2}$ (25 mg/kg), a cada seis horas por via intravenosa durante dois dias (caso1); (4) estreptomicina ${ }^{3}(10 \mathrm{mg} / \mathrm{kg}$ a cada 12 horas por via IM durante 7 dias), além de transfusão sanguínea. Foram transfundidos 2 e 3 litros de sangue total nos casos 1 e 2, respectivamente após o exame clínico inicial. A auscultação pulmonar do caso 1 retornou a normalidade a partir do sexto dia de internamento.
Sete dias após o atendimento clínico inicial, ambos os animais receberam alta.

\section{Discussão e conclusões}

Hematúria é definida como a presença anormal de eritrócitos na urina. A hematúria macroscópica constitui manifestação clínica de grande significado, pois relaciona-se a doenças importantes do trato urinário. Além disso, dependendo da intensidade, pode determinar descompensação hemodinâmica exigindo, consequentemente, medidas emergenciais para o diagnóstico e tratamento.

Tabela 2:Valores bioquímicos no primeiro e sétimo dia após atendimento clínico de casos de hematúria macroscópica associada a infecção por Leptospira interrogans sorogrupo Canicola.

\begin{tabular}{|c|c|c|c|c|c|}
\hline & \multicolumn{2}{|c|}{ Caso 1} & \multicolumn{2}{|c|}{ Caso 2} & \multirow[b]{2}{*}{ Valores de referência } \\
\hline & $1^{\circ} \mathrm{dia}$ & $7^{\circ}$ dia & $1^{\circ} \mathrm{dia}$ & $7^{\circ}$ dia & \\
\hline Proteínas totais & 8,6 & 6,1 & 5,7 & 7,0 & $6,0-8,0 \mathrm{~g} / \mathrm{dl}$ \\
\hline Uréia & 98 & 78,0 & 86 & 41 & $10-24 \mathrm{mg} / \mathrm{dl}$ \\
\hline Creatinina & 3,1 & 1,1 & 3,0 & 2,3 & $1,2-1,9 \mathrm{mg} / \mathrm{dl}$ \\
\hline GGT & 60 & 34,0 & 52 & 46 & 3-23 UI/I \\
\hline Fosfatase alcalina & 150 & 370 & 147 & 643 & 86-295 UI/I \\
\hline \multicolumn{6}{|l|}{ Bilirrubina } \\
\hline Conjugada (direta) & - & - & 0,2 & 0,18 & $0-0,4 \mathrm{mg} / \mathrm{dl}$ \\
\hline Não-conjugada (indireta) & - & - & 5,0 & 5,9 & $0,2-2,0 \mathrm{mg} / \mathrm{dl}$ \\
\hline Total & - & - & 5,2 & 6,08 & $0-2,4 \mathrm{mg} / \mathrm{dl}$ \\
\hline Magnésio total & - & - & 1,6 & 2,9 & $1,4-2,3 \mu \mathrm{g} / \mathrm{dl}$ \\
\hline
\end{tabular}

'Transamin, Química e Farmacêutica Nikkho do Brasil, Rio de Janeiro, Rio de Janeiro.
${ }^{2}$ Analgex V, União Química Farmacêutica Nacional, Embu-Guaçu, São Paulo. ${ }^{3}$ Estreptomax, Ouro Fino Saúde Animal, Cravinhos, São Paulo. 
Nos seres humanos, a hematúria pode ser visível a partir de uma concentração tão baixa quanto $1 \mathrm{ml}$ de sangue por litro de urina (BOLENS et al., 2018), no entanto, não há informações sobre tal quantidade no equino. No momento do exame clínico inicial é importante descartar outras causas de descoloração da urina, à exemplo da mioglobinúria associada aos quadros de rabdomiólise (MELO et al., 2009b) ou hemoglobinúria secundária à hemólise.

No presente relato, fitas reagentes para urinálise (dipsticks) foram utilizadas para diferenciação da descoloração da urina no momento do exame clínico inicial, além de terem demonstrado presença de proteinúria, glicosúria e piúria (leucócitos). Segundo Bolens et al. (2018) tal ferramenta auxiliar de diagnóstico é muito sensível para a identificação de hemácias na urina. No entanto, Melo e Vaz (2021) ao avaliarem diferentes marcas de tiras reagentes relativo à densidade e à análise química da urina de cães e gatos recomendam que estas devam ser utilizadas apenas como ferramenta de triagem.

Vários achados sugeriram leptospirose como causa da hematúria macroscópica. A combinação de febre, leucocitose, proteinúria, glicosúria e piúria são compatíveis com doença inflamatória do trato urinário, vistos comumente nos casos de leptospirose. Por outro lado, elevação das concentrações séricas de uréia e creatinina são compatíveis com quadro de necrose ou nefrite intersticial/tubular, achados comuns nos casos agudos de leptospirose (SMITH et al., 2017).

Além desses fatores, ambos animais foram considerados positivos no teste de Soro Aglutinação Microscópica, apesar da baixa titulação (1:400). Segundo Brasil (1995), quando não houver a disponibilidade de 2 ou mais amostras para a realização da sorologia pareada, títulos menores (1:100 a 1:800) devem ser considerados de acordo com a situação clínico-epidemiológica para que o diagnóstico seja realizado. Portanto, a associação dos sinais clínicos, dados epidemiológicos e sorologia foi indispensável para estabelecimento do diagnóstico em ambos os casos. Ajjimarungsi et al. (2020) utilizaram um índice de titulação igual ou superior a 1:400 como um dos critérios de soropositividade em seres humanos, corroborando com o critério adotado no presente relato. Braga et al. (2011) ao determinar a associação entre alterações oftalmológicas e sororreatividade à leptospirose pelo sorogrupo Icterohaemorrhagiae em equinos adotaram a titulação de 1:200 como critério de soropositividade.

Leucocitose, hiperbilirrubinemia (icterícia), elevação da concentração sérica de fosfatase alcalina, piúria, glicosúria, proteinúria e hematúria são achados inespecíficos da leptospirose (BECIROVIC et al., 2020). No entanto, quando avaliados em conjunto com dados epidemiológicos e resultados sorológicos podem confirmar o diagnóstico (AHMAD et al., 2005). Os achados corroboram os dados de Divers et al. (1992) e Bernard et al. (1993) que relataram casos isolados de leptospirose equina com presença de disfunção renal e hematúria.

Evidência sorológica de exposição dos equinos à Leptospira interrogans é comum, embora manifestações clínicas dessa exposição sejam raramente descritas (LINHARES et al., 2005). A leptospirose é uma zoonose mundialmente distribuída, sendo considerada endêmica nas áreas tropicais. Ocorre em formas de surtos em comunidades de baixa renda, principalmente após períodos de altos índices pluviométricos e, no presente relato, a manifestação clínica em ambos os casos ocorreu durante a época de altos índices pluviométricos (verão). Alguns animais domésticos atuam como reservatórios para alguns sorogrupos como os bovinos para Sejroe, Pomona e Grippotyphosa, e os cães para Canicola. Este último sorogrupo está associado a síndromes hemolíticas e hemoglobinúria (SPANGA et al., 2019).

Apesar de ratos (Rattus norvegicus) atuarem como reservatórios do patógeno e serem a principal fonte de infecção para várias espécies, sabe-se que os cães também desempenham este papel (SPANGA et al., 2019). Miotto et al. (2018), após isolarem leptospiras da urina de cães assintomáticos, sugeriram a participação dessa espécie como reservatório e fonte de infecção. Os dados epidemiológicos dos casos relatados demonstram o estreito contato dos dois equinos com uma população de cães errantes, os quais atuaram, provavelmente, como a fonte de infecção.

No presente relato, os dois equinos manifestaram diferentes formas clínicas da leptospirose, ictérica (caso 1) e anictérica (caso 2), com sintomatologia clínica semelhante (hematúria, azotemia, letargia). Embora seja esperado que os sinais clínicos da leptospirose sejam semelhantes, o mesmo sorogrupo pode induzir diferentes apresentações clínicas (FERREIRA et al., 2008), conforme observado neste relato. Covic et al. (2003) relata uma ampla variedade de manifestações clínicas de diátese hemorrágica em seres humanos com leptospirose grave incluindo gengivorragia, melena, hematêmese e hematúria macroscópica, isoladamente ou associadas. No presente relato, a única manifestação clínica de diátese hemorrágica foi hematúria macroscópica que provavelmente está relacionada à lesão do endotélio vascular renal permitindo a passagem de sangue para a pelve renal.

Outro achado comum foi o discreto aumento de tamanho do rim esquerdo associado à intensa sensibilidade dolorosa, identificados à palpação transretal, e aparentemente, ambos os achados estão associados a quadro inflamatório renal agudo. Característica precoce nos casos de leptospirose são achados ultrasonográficos que mostram rins aumentados de tamanho e parênquima sem alterações significativas de ecogenicidade (DAHER et al., 2010), conforme observado neste relato.

A elevação do tempo de perfusão capilar em ambos os casos denota quadro de desidratação. A desidratação é um achado frequente na leptospirose, muitas vezes, associada à ocorrência de febre. Fenômenos hemorrágicos associados à lesão endotelial também contribuem para a ocorrência da hipovolemia (DAHER et al., 2010). Supõe-se, neste relato, que a hipovolemia ocorreu secundária a combinação de febre e hematúria. A utilização da fluidoterapia enteral foi eficaz no restabelecimento da volemia bem como na resolução da compactação, corroborando com achados de outros estudos (DIAS et al., 2019). A quantidade de fluido a ser administrado levou em consideração o cálculo do déficit hídrico, bem como o fornecimento da taxa de manutenção de $60 \mathrm{ml} / \mathrm{kg}$ conforme sugerido por Melo et al. (2010).

O quadro de azotemia (elevação da concentração sérica de uréia e creatinina) nos dois casos pode ter ocorrido secundário a redução da perfusão renal por lesões isquêmicas e diminuição da taxa de filtração glomerular associadas à destruição das células do epitélio renal por toxinas e componentes da membrana das leptospiras. Yücel Koçak et al. (2018) relatam que as lipoproteínas da leptospira ativam o receptor do tipo Toll-like disparando respostas inflamatórias nas células tubulares renais. 
O comprometimento renal evidenciado pelo aumento nos níveis séricos de uréia e creatinina é achado frequente nos casos de leptospirose aguda, caracterizando um quadro de insuficiência renal aguda (IRA). A normalização da concentração desses dois metabólitos ocorre, geralmente, na segunda semana depois da manifestação clínica da doença (DAHER et al., 2010), justificando a presença de níveis elevados de uréia e creatinina no momento da alta hospitalar de ambos os casos.

Recentemente, Farias et al. (2020) não observaram diferenças significativas estatisticamente em alguns parâmetros hematológicos ou bioquímicos entre animais soropositivos assintomáticos e soronegativos para Leptospira interrogans. Dessa forma, a interpretação de resultados laboratoriais deve ser realizada em conjunto com os achados do exame clínico.

O envolvimento renal nos casos de leptospirose pode variar de um curso subclínico com leve proteinúria e alterações no sedimento urinário a um quadro de IRA grave. A IRA se apresenta frequentemente com rápida elevação da concentração sérica de uréia e creatinina e podem estar associadas com icterícia (DAHER et al., 2010; YÜCEL KOÇAK et al., 2018).

A microscopia de campo escuro foi negativa em ambos os casos. Esse método diagnóstico raramente se apresenta positivo nos seres humanos com insuficiência renal aguda induzida por leptospirose (LECOUR et al., 1989). Divers et al. (1992) e Bernard et al. (1993) também relatam ausência de positividade deste teste em casos clínicos de leptospirose equina.

Asíndrome de Weil é a forma mais grave da doença, manifestandose clinicamente por febre, diátese hemorrágica, insuficiência renal aguda, icterícia, disfunção hepática e hemodinâmica (YÜCEL KOÇAK et al., 2018). Com base na manifestação clínica de desordem hemorrágica (hematúria), insuficiência renal aguda e icterícia pode-se inferir que um dos animais (caso 1) desenvolveu síndrome clínica semelhante à Síndrome de Weil, embora esta última não seja relatada nos equinos. A exposição de animais susceptíveis aos sorotipos não adaptados ao hospedeiro resulta em doença incidental culminando em manifestação de sintomatologia clínica grave (FERREIRA et al., 2008).

Icterícia é um achado comum na leptospirose, e a concentração de bilirrubina está diretamente relacionada à extensão da lesão renal (DAHER et al., 2010). Embora a icterícia tenha sido identificada apenas em um animal (caso 1), o segundo equino (caso 2) apresentava concentração de bilirrubina sérica duas vezes superior ao limite de referência da espécie sem manifestação clínica de icterícia.

Hipomotilidade intestinal e compactação de cólon menor foram identificadas em ambos os casos. Aparentemente, não

\section{Referências}

AHMAD, S.N.; SAHA, S.; AHMAD, F.M.H. Laboratory diagnosis of leptospirosis. Journal of postgraduate medicine, v. 51, n. 3, p. 195-200, 2005.

AJJIMARUNGSI, A.; BHURAYANONTACHAI, R.; CHUSRI, S. Clinical characteristics, outcomes, and predictors of leptospirosis in patients admitted to the medical intensive care unit: A retrospective analysis. Journal of infection and public health, $\mathrm{v}$. 13, n. 12, p.2055-2061, 2020. existe relação direta entre leptospirose e alteração da função gastrointestinal. É provável que a hipomotilidade tenha ocorrido secundária a hiperatividade simpática e dopaminérgica, resultando em diminuição da motilidade propulsiva e aumento do tônus dos esfíncteres do trato gastrintestinal (MELO et al., 2007), ou secundária a hipovolemia (FERREIRA et al., 2009). No entanto, quadros de leptospirose aguda estão associados à inanição e, recentemente, foi demonstrado que ausência de ingestão alimentar resulta em quadro de hipomotilidade intestinal nos equinos (DI FILIPPO et al., 2021; MELO et al., 2021).

Um equino (caso 1) apresentou alteração na auscultação pulmonar sugestiva de pneumopatia. Envolvimento pulmonar na leptospirose é relatado em cerca de $20 \%-70 \%$ dos pacientes humanos e ocorre secundária a disfunção renal e hepática manifestando-se como status imuno-mediado incluindo pneumonia leve a moderada, hemorragia alveolar, hemoptise, síndrome da angústia respiratória grave, entre outros (BAO et al., 2021; SOLER et al., 2021).

Embora nenhuma definição consensual sobre a síndrome da resposta inflamatória sistêmica (SIRS) no equino esteja disponível atualmente, exemplos de critérios publicados usados para diagnosticar SIRS incluem dois ou mais dos seguintes em equinos adultos: 1) Temperatura corporal $>38,6 \circ \mathrm{C}$; 2) Frequência cardíaca > 60 batimentos / min; 3) Hiperventilação (frequência respiratória $>30$ respirações / min) e 4) Contagem de leucócitos $>12.500$ células / $\mu$ l ou $<4.500$ células/ $\mu$ l (Epstein et al., 2011; Sheats, 2019). Com base nesses critérios de diagnóstico, os dois animais no presente relato apresentaram quadro clínico de SIRS.

Aocorrência de SIRS na leptospirose equina não é frequentemente relatada, uma vez que a maioria dos casos cursa de forma assintomática ou na forma de abortos em éguas sem que ocorra maiores complicações. No entanto, a ocorrência de SIRS e choque séptico associado a leptospirose é frequentemente relatado (DUARTE-NETO et al., 2019). Este achado ressalta a importância da inclusão da leptospirose na lista de diagnósticos diferenciais de equinos com quadro clínico caracterizado por febre, leucocitose, taquicardia e taquipneia, associados ou não à presença de icterícia.

O diagnóstico e a instituição de terapia adequada de forma precoce são os pontos chaves nos casos de hematúria macroscópica associada à leptospirose. O protocolo terapêutico instituído foi adequado em reverter o quadro de hematúria e eliminar a infecção. Medidas sanitárias devem ser implantadas nas propriedades de modo a diminuir à exposição dos equinos à possíveis fontes de infecção de Leptospira sp.

BAO, Q.H.; YU, L.; DING, J.J.; CHEN, Y.J.; WANG, J.W.; PANG, J.M.; JIN, Q. Severe community-acquired pneumonia caused by Leptospira interrogans: A case report and review of literature. World Journal of Clinical Cases, v. 9, n. 8, p. 1901-1908, 2021.

BATISTA, J.S.; PAIVA, C.C.P.L.; SILVA, J. B.; COSTA, A.M.; CAVALCANTE, P.H.; PRAÇA, L.M.; OLINDA, R.G.; PAIVA, K.A.R. Avaliação de cinco casos de abortamento associado à leptospirose em éguas no Rio Grande do Norte. Revista Brasileira de Ciência Veterinária, v. 22, n. 3-4, p. 165-170, 2015. 
BRAGA, J.; HAMOND, C.; MARTINS, G.; ABREU, R.N.; LILENBAUM, W. Ophthalmic alterations in horses with leptospirosis by serovar Icterohaemorrhagiae in Rio de Janeiro, Brazil. Pesquisa Veterinária Brasileira, v. 31, n. 2, p.147-150, 2011. BECIROVIC, A.; NUMANOVIC, F.; DZAFIC, F.; PILJIC, D. Analysis of clinical and laboratory characteristics of patients with leptospirosis in five-year period. Materia socio-medica, v. 32, n. 1, p. 15-19, 2020.

BERNARD, W.V.; WILLIAMS, D.; TUTTLE, P.A.; PIERCE, $\mathrm{S}$. Hematuria and leptospiruria in a foal. Journal of American Veterinary Medical Association, v. 203, n. 2, p. 276-278, 1993.

BRASIL. Ministério da Saúde. Centro Nacional de Epidemiologia. Programa Nacional de Leptospiroses. Manual de Leptospirose. 2 ed. Brasília: Fundação Nacional de Saúde, 98p., 1995.

COVIC, A.; GOLDSMITH, D.J.; GUSBETH-TATOMIR, P.; SEICA, A.; COVIC, M. A retrospective 5-year study in Moldova of acute renal failure due to leptospirosis: 58 cases and a review of the literature. Nephrology, dialysis, transplantation, v. 18, n. 6, p. 1128-1134, 2003.

DAHER, E.F.; ABREU, K.L.S.A.; JUNIOR, G.B.S. Insuficiência renal aguda associada à leptospirose. Jornal Brasileiro de Nefrologia, v. 32, n. 4, p. 408-415, 2010.

DIAS, D.C.R.; MOREIRA, N.S.; CALMON, T.C.B.S.; OLIVEIRA, D.P.; ERMITA, P.A.N.; SILVA, M.O.; FONSECA, L.A.; RIBEIRO FILHO, J.D. Avaliação comparativa entre diferentes modalidades de reposição hidroeletrolítica em equinos desidratados experimentalmente pela utilização de parâmetros do exame físico e marcadores hematológicos. Revista Brasileira de Ciência Veterinária, v. 26, n. 1, p. 34-41, 2019.

DI FILIPPO, P.A.; DUARTE, B. R.; ALBERNAZ, A. P.; QUIRINO, C.R. Effects of feed deprivation on physical and blood parameters of horses. Brazilian Journal of Veterinary Medicine, v. 43, n. 1, e000321, 2021.

DIVERS, T.J.; BYARS, T.D.; SHIN, S.J. Renal dysfunction associated with infection of Leptospira interrogans in a horse. Journal of American Veterinary Medical Association, v. 201, n. 9, p. 1301-1392, 1992.

DUARTE-NETO, A.N.; CRODA, J.; PAGLIARI, C.; SORIANO, F.G.; NICODEMO, A.C.; DUARTE, M. Severe leptospirosis features in the spleen indicate cellular immunosuppression similar to that found in septic shock. Frontiers in immunology, v. 10, 920, 2019.

EPSTEIN, K.L.; BRAINARD, B.M.; GOMEZ-IBANEZ,

S.E.; LOPES, M.A.; BARTON, M.H.; MOORE, J.N.

Thrombelastography in horses with acute gastrointestinal disease. Journal Veterinary Internal Medicine, v. 25, n. 2, p. 307-14, 2011.

FARIAS, D.K.; LOVATEL, M.; DALMINA, A.C.; BUNN, S.; RECK, C.; MENIN, A.; SAITO, M.E. Metabolismo oxidativo e alterações hematobioquímicas em equinos com leptospirose subclínica. Archives of Veterinary Science, v. 25, n. 4, p. 91-103, 2020.

FERREIRA, C.; PALHARES, M.S.; MELO, U.P.; GHELLER, V.A.; BRAGA, C.E. Cólicas por compactação em equinos: etiopatogenia, diagnóstico e tratamento. Acta Veterinaria Brasilica, v. 3, n. 3, p. 117-126, 2009.

FERREIRA, C.; PALHARES, M.S.; MOREIRA, E.C.; MELO, U.P.; SILVA FILHO, J. M. Leptospirose em equinos. A Hora Veterinária, v. 163, p. 25-28, 2008.

FOUCHÉ, N.; GRAUBNER, C.; LANZ, S.; SCHWEIGHAUSER, A.; FRANCEY, T.; GERBER, V. Acute kidney injury due to Leptospira interrogans in 4 foals and use of renal replacement therapy with intermittent hemodiafiltration in 1 foal. Journal of Veterinary Internal Medicine, v. 34, n. 2, p. 1007-1012, 2020

FURLANELLO, T.; REALE, I. First description of reactive arthritis secondary to leptospirosis in a dog. Iranian Journal of Veterinary Research, v. 21, n. 2, p. 146-149, 2020.
LASTA, C.S.; OLIVEIRA, S.T.; MERINI, L.P.; DASSO, M.G.; PEDRALLI, V.; GONZALEZ, F.H.D. Pesquisa de aglutininas anti-Leptospira em soros de equinos de tração em Porto Alegre, Brasil. Revista Brasileira de Ciência Veterinária, v. 20, n. 1, p. 23-25, 2013.

LECOUR, H.; MIRANDA, M., MAGRO, C.; GONÇALVES, V.; $\mathrm{ROCHA}, \mathrm{A}$. Human leptospirosis - a review of 50 cases. Infection, v. 17 , n. 1 , p. 10-14, 1989.

LEVETT, P.N. Leptospirosis. Clinical Microbiology Reviews, v. 14, n. 2, p. 296-326, 2001.

LINHARES, G.F.C.; GIRIO, R.J.S.; LINHARES, D.C.L.; MONDEIRO, L.C.; OLIVEIRA, A.P.A. Sorovares de Leptospira interrogans e respectivas prevalências em cavalos da microrregião de Goiânia, GO. Ciência Animal Brasileira, v. 6, n. 4, p. 255-259, 2005.

MACÊDO, J.T.S.A.; BISCARDE, C.E.A.; NASCIMENTO, K.A.; FERREIRA JÚNIOR, J.A.; PEDROSO, P.M.O. Uretrolitíase obstrutiva em equino. Acta Scientiae Veterinariae. v. 45 (Suppl 1), 238, 2017.

MELO, H.M.; VAZ, A.F.M. Desempenho de diferentes marcas de tiras reagentes relativo à densidade e à análise química da urina de cães e gatos. Revista Brasileira de Ciência Veterinária, v. 28, n. 1, p. 57-60, 2021.

MELO, U.P.; PALHARES, M.S.; FERREIRA, C.; GHELLER, V.A.; LEME, F.O.P. Efeitos da nutrição parenteral ou enteral, associadas ou não à glutamina, sobre a motilidade gastrintestinal em equinos submetidos à inanição e realimentação. Revista Brasileira de Ciência Veterinária, v. 26, n. 2, p. 69-74, 2021.

MELO, U.P.; FERREIRA, C.; PALHARES, M.S.; SILVA FILHO, J.M. Choque circulatório em equinos. Semina. Ciências Agrárias, v. 31, n. 1, p. 205-230, 2010.

MELO, U.P.; FIÓRIO, R.C.; ARAÚJO, T.B.S.; FERREIRA, C. Intoxicação por fenilbutazona em equino: relato de caso. Acta Veterinaria Brasilica, v. 3, n. 2, p. 111-116, 2009a.

MELO, U.P.; FERREIRA, C.; FANTINI, P.; BORGES, K.D.A. Icterícia de íris após rabdomiólise por esforço em um equino. Ciência Rural, v. 39, n. 7, p. 2213-2217, 2009b.

MELO, U.P.; FERREIRA, C.; PALHARES, M.S. Motilidade gastrointestinal equina: fisiologia, mecanismos de disfunção e efeito da administração de diferentes fármacos. Revista CFMV, v. 41, n. 1, p. 41-58, 2007.

MIOTTO, B.A.; GUILLOUX, A.G.A.; TOZZI, B.F.; MORENO, L.Z.; DA HORA, A.S.; DIAS, R.A.; HEINEMANN, M.B.; MORENO, A.M.; FILHO, A.F.S.; LILENBAUM, W.; HAGIWARA, M.K. Prospective study of canine leptospirosis in shelter and stray dog populations: identification of chronic carriers and different Leptospira species infecting dogs. PLoS One, v.13, n.7, p.1-23, 2018.

SHEATS, M.K. A comparative review of equine SIRS, sepsis, and neutrophils. Frontiers in veterinary science, v. 6, 69, 2019.

SOLER, M.C.; MOGLIANI, S.; BENITEZ, S.T.; CABILLÓN, L.N.; ROLLIÉ, R.D.; MARTINS, G.M. Glucocorticoides en hemorragia alveolar por leptospira. Medicina, v. 81, n. 1, p. 107-110, 2021.

SPANGA, M.L.; COSTA, D.F.; AZEVEDO, S.S.; MELO, A.L.T.; AGUIAR, D.M.; CAMARGO, L.M. Soropositividade para Leptospira sp. e sorogrupos predominantes em cães do Pantanal Brasileiro. Revista Brasileira de Ciência Veterinária, v. 26, n. 1, p. 46-50, 2019.

YÜCEL KOÇAK, S.; KUDU, A.; KAYALAR, A.; YILMAZ, M.; APAYDIN, S. Leptospirosis with acute renal failure and vasculitis: a case report. Archives of rheumatology, v. 34, n. 2, p. 229-232, 2018. 